\title{
Time course of changes in VंO2peak and O2 extraction during ramp cycle exercise following HIIT vs moderate-intensity continuous training in type 2 diabetes
}

Norita Gildea

Adam McDermott

Joel Rocha

Donal O'Shea

Simon Green

Mikel Egaña

This is the accepted manuscript (C) 2021, American Physiological Society

Gildea, N., McDermott, A., Rocha, J., O'Shea, D., Green, S. \& Egaña, M. (2021) 'Time course of changes in VO2peak and $\mathrm{O} 2$ extraction during ramp cycle exercise following HIIT vs moderate-intensity continuous training in type 2 diabetes'. American Journal of Physiology.

The published article is available from DOI: https://doi.org/10.1152/ajpregu.00318.2020 


\section{TITLE}

2 Time course of changes in $\dot{\mathrm{V}} \mathrm{O}_{2 \text { peak }}$ and $\mathrm{O}_{2}$ extraction during ramp cycle exercise following HIIT

3 vs moderate-intensity continuous training in type 2 diabetes.

\section{AUTHORS}

5 Norita Gildea $^{1}$, Adam McDermott ${ }^{1 *}$, Joel Rocha ${ }^{2}$, Donal O’Shea ${ }^{3,4}$, Simon Green ${ }^{5}$, Mikel Egaña ${ }^{1}$

\section{AFFILIATIONS \& ADDRESSES}

7 1. Department of Physiology, School of Medicine, Trinity College Dublin, Dublin 2, Ireland.

8 2. Division of Sport and Exercise Sciences, Abertay University, Dundee, UK.

9 3. Department of Endocrinology, St. Columcille's Hospital, Dublin, Ireland.

10 4. Department of Endocrinology and Diabetes Mellitus, St. Vincent's University Hospital, 11 Dublin, Ireland.

12 5. Schools of Health Sciences and Medicine, Western Sydney University, Sydney, Australia.

$13 * \mathrm{~N}$ Gildea and A McDermott contributed equally to this work

\section{CONTACT INFORMATION (corresponding author):}

16 Mikel Egaña

17 Department of Physiology, School of Medicine; Trinity College Dublin, Dublin 2, Ireland.

18 E-mail: megana@tcd.ie; Telephone: +353 1896 1770; Fax: +3531679 3545

\section{RUNNING HEAD:}

21 HIIT vs MICT on $\dot{\mathrm{V}}_{2 \text { peak }} \&$ fractional $\mathrm{O}_{2}$ extraction in T2D 


\section{Abstract}

24 In the present study we assessed the time course of adaptations in peak oxygen uptake $\left(\dot{\mathrm{V}}_{2 \text { peak }}\right)$ 25 and muscle fractional oxygen $\left(\mathrm{O}_{2}\right)$ extraction (using near-infrared spectroscopy) following 12 26 weeks of low-volume high-intensity interval training (HIIT) vs. moderate-intensity continuous 27 endurance training (MICT) in adults with uncomplicated type 2 diabetes (T2D). Participants with 28 T2D were randomly assigned to MICT $(n=12,50 \mathrm{~min}$ of moderate-intensity cycling), HIIT $(n=$ $299,10 \times 1$ min at $\sim 90 \%$ maximal heart rate) or to a non-exercising control group $(n=9)$. Exercising 30 groups trained 3 times per week and measurements were taken every 3 weeks. The rate of muscle 31 deoxygenation (i.e. deoxygenated haemoglobin and myoglobin concentration, $\Delta[\mathrm{HHb}+\mathrm{Mb}]$ ) 32 profiles of the vastus lateralis muscle were normalised to $100 \%$ of the response, plotted against $\%$ 33 power output (PO) and fitted with a double linear regression model. $\dot{\mathrm{V}} \mathrm{O}_{2 \text { peak }}$ increased $(P<0.05)$

34 by week 3 of MICT $(+17 \%)$ and HIIT $(+8 \%)$, with no further significant changes thereafter. Total 35 increases in $\dot{\mathrm{V}} \mathrm{O}_{2 \text { peak }}$ posttraining $(P<0.05)$ were $27 \%$ and $14 \%$ respectively. The $\% \Delta[\mathrm{HHb}+\mathrm{Mb}]$ 36 vs \%PO slope of the first linear segment $\left(\right.$ slope $\left._{1}\right)$ was reduced $(P<0.05)$ beyond 3 weeks of HIIT 37 and MICT with no further significant changes thereafter. No changes in $\dot{\mathrm{VO}}_{2 \text { peak }}$ or slope were $_{1}$ 38 observed in the control group. Low-volume HIIT and MICT induced improvements in $\dot{\mathrm{V}}_{2 \text { peak }}$ 39 following a similar time course and these improvements were likely, at least in part, due to an 40 improved microvascular $\mathrm{O}_{2}$ delivery.

42 Keywords: cardiorespiratory fitness, high-intensity interval training, muscle deoxygenation, near-infrared spectroscopy, exercise tolerance. 


\section{Introduction}

45 The last two decades have seen an unprecedented global increase in type 2 diabetes (T2D) 46 rendering this disease a major public health and economic burden of the $21^{\text {st }}$ century. This is a 47 direct consequence of the metabolic complexities and underlying comorbidities associated with 48 T2D, with which approximately 366 million people worldwide live. Specifically, these individuals 49 have an increased propensity for the development of coronary artery, cerebrovascular and 50 peripheral vascular disease $(13,46)$. A critical concern among individuals with T2D is the 51 consistent demonstration of significantly reduced $(\sim 20 \%)$ peak oxygen uptake $(\dot{\mathrm{V} O}$ 2peak $)(3,20$, $5230,42,43,50)$ an established independent prognostic marker for cardiovascular and all-course 53 mortality within this clinical population (64).

55 The impairments in $\dot{\mathrm{VO}}_{2 \text { peak }}$ in $\mathrm{T} 2 \mathrm{D}$ might be influenced by cardiovascular limitations at a systemic 56 level, such as impaired left ventricular filling $(68,69)$, and limitations in peripheral vasodilation 57 and/or microvascular function in the lower limbs $(5,18,19,25,27,32,49,52,65)$. Regarding 58 peripheral $\mathrm{O}_{2}$ delivery constraints, Kiely et al. (26) initially reported reduced peak leg 59 haemodynamic and vasodilatory responses during an incremental calf plantar-flexion exercise in 60 uncomplicated T2D. More recently, Gildea et al. (18), reported a significant reduction in $\dot{\mathrm{V}} \mathrm{O}_{2 \text { peak }}$ 61 accompanied by a greater reliance in fractional oxygen extraction during ramp incremental cycling 62 exercise, in a similar cohort of individuals with T2D compared with healthy controls. This was 63 depicted by an increased near-infrared spectroscopy (NIRS)-derived rate of muscle deoxygenation 64 (i.e., deoxygenated haemoglobin and myoglobin, $[\mathrm{HHb}+\mathrm{Mb}]$ ) which is suggestive of lower 65 microvascular blood flow responses likely due to maldistribution of active muscle blood flow in 66 T2D (18). 
67 Exercise training is an important therapeutic modality in T2D because it elicits the most effective

68 increases in exercise tolerance and cardiorespiratory fitness (11). In this regard, short-term (8-12

69 weeks), traditional endurance training interventions, involving $\sim 150 \mathrm{~min}$ of continuous exercise

70 per week, often termed moderate-intensity continuous training (MICT) despite exercise intensity

71 not being prescribed relative to 'metabolic thresholds', have been shown to significantly increase

$72 \dot{\mathrm{V}} \mathrm{O}_{2 \text { peak }}$ in uncomplicated T2D by $\sim 18 \%$ (ranging from 8 to $27 \%$ ) $(10,21,31,37,70$ ). However,

73 adherence to these time-oriented MICT guidelines is poor (61), with "lack of time" regularly cited

74 as one of the key barriers (58). With this in mind, more recently, attention has been given to the

75 intensity of exercise, with time efficient, low-volume high-intensity interval training (HIIT)

76 interventions (involving $\sim 75$ min per week of intermittent brief periods of vigorous exercise)

77 eliciting similar improvements in $\dot{\mathrm{V}} \mathrm{O}_{2 \text { peak }}$ of $\sim 16 \%$ (ranging from 7 to $25 \%$ ) in $\mathrm{T} 2 \mathrm{D}(15,34,37$,

$7851,67,70)$. However, while low volume HIIT and MICT interventions are effective at inducing

79 improvements in cardiorespiratory fitness in T2D, the time course of effects and the mechanisms

80 underlying the increases in $\mathrm{V}_{2 \text { peak }}$ following these exercise training interventions in $\mathrm{T} 2 \mathrm{D}$ are

81 presently unknown. Accordingly, the primary aim of the present study was to assess the time

82 course and mechanisms of adaptations in cardiorespiratory fitness subsequent to a 12 week MICT

83 vs HIIT intervention in uncomplicated T2D. To shed light on whether peripheral microvascular

84 function influences the changes in $\dot{\mathrm{VO}}_{2 \text { peak }}$ in $\mathrm{T} 2 \mathrm{D}$, the rates of muscle deoxygenation were

85 assessed. We hypothesised that both training interventions would enhance $\dot{\mathrm{VO}}_{2 \text { peak }}$ by reducing the 86 rates of muscle deoxygenation early in training.

87

88 Methods 


\section{Participants}

90 Participants were recruited from the Diabetes Outpatient Clinics of St. Columcille's and St.

91 Vincent's University Hospitals (Dublin). Participant's eligibility was initially checked following 92 chart review. Specifically, participants were included if they had a clinical history of diabetes < $9311 \mathrm{yr}$, were untrained and had $\mathrm{HbA}_{1 \mathrm{c}}$ levels of $<10 \%$. Participants were excluded if they were 94 treated by exogenous insulin, were smokers, had a disease contraindicating physical training, or demonstrated evidence of renal, liver or cardiovascular disease.

The overall process of recruitment and allocation to experimental groups is shown in Fig 1. Three hundred individuals with T2D were eligible for inclusion (by prior chart review) and were briefly informed about the study initially by hospital consultants when they attended their outpatient clinics. If individuals were interested they were then directed to the study investigators who were

101 present in the waiting area of the clinics. Fifty-nine individuals expressed interest in participating in the study. These individuals completed a 12-lead electrocardiogram treadmill stress test at St. Columcille's Hospital. Twelve of these 59 participants failed the treadmill exercise stress test while 12 other participants who passed the exercise stress test decided to opt out from the study before completing the pretraining laboratory assessments. Thus, 35 participants completed the baseline laboratory assessments and were given opaque sealed envelopes randomly allocating them to one of the 3 intervention groups (MICT, initially $n=13$; HIIT, initially $n=10$ or Control,

108 initially $n=12$;). Eight participants dropped out of the study for personal reasons unrelated to the experiment (Control, $n=3$; HIIT, $n=3$; MICT, $n=2$ ). Participants in the Control group were

110 offered re-randomisation to one of the exercise training groups after the intervention period of 111 which 3 accepted (HIIT, $n=2$; MICT, $n=1$ ) and subsequently completed the respective training 
112 intervention. The final study population consisted of 27 participants undergoing the intervention,

113 of whom 3 underwent both Control and either HIIT or MICT. Thus, 30 completed responses from

114 the study intervention were included for statistical analysis (Control, $n=9$; HIIT, $n=9$; MICT, $n$

$115=12$ ). All participants provided written informed consent prior to participation. The study was

116 approved by the Faculty of Health Sciences' Research Ethics Committee, Trinity College Dublin,

117 and St Vincent's Healthcare Ethics and Medical Research Committee, and conducted in 118 accordance with the principles outlined by the Declaration of Helsinki.

120 Exercise interventions

121 Overview. Participants in the HIIT and MICT groups carried out a 12-week supervised exercise 122 intervention, training 3 times per week on non-consecutive days at a local health and fitness centre 123 in Co. Dublin, whereas participants in the Control group received no intervention and continued 124 with their normal daily routine. All exercise training sessions were supervised by a study 125 investigator. Training intensity was adjusted at 3-week intervals (i.e. every 9 sessions) to reflect 126 changes in fitness levels. Participants were equipped with a heart rate monitor (Cardiosport, USA)

127 to adhere to the prescribed exercise intensity. Both exercise groups completed a 5 min warm up 128 and 5 min cool down before and after each session on an aerobic machine of their choice (elliptical, 129 treadmill, rowing or cycle ergometer). The main component of each training session was 130 completed on a cycle ergometer as follows:

131 Low-volume high-intensity interval training: The HIIT group completed $10 \times 60$-s bouts of high-

132 intensity cycling interspersed by 60 -s of light cycling. The high-intensity bout was completed at a

133 PO equivalent to $70 \%$ of the difference between participant's peak power output $\left(\mathrm{PO}_{\text {peak }}\right)$ and the

134 PO at ventilatory threshold (VT) $(70 \% \Delta)$ achieved during the ramp exercise test (see testing). This 
135 output was designed to elicit a target heart rate of $\sim 90 \% \mathrm{HR}_{\max }$ during the high-intensity bouts,

136 and participants were expected to exercise in the severe-intensity domain.

137

138 Continuous training: Each MICT session comprised of 50 minutes of cycling at a PO equivalent 139 to $\sim 80-90 \%$ VT as calculated from the ramp test (see testing). Therefore, the total monthly time 140 commitment (including warm up) for the low-volume HIIT group was $\sim 300$ min while for the 141 MICT group was $\sim 660$ min.

142

\section{Testing}

144 Initially, physical activity levels were assessed by the use of 5-day RT3 triaxial accelerometry

145 (Stayhealthy Inc, CA) (Table 1). The threshold for sedentary or inactive behaviour $(<1.5$ metabolic 146 equivalents or METs) was set as < 100 counts/min (4), counts/min between 101 and 1317 were

147 considered light activity (1.5-3 METs); and counts/min $>1317$ corresponded to moderate-to148 vigorous physical activity ( $>3$ MET) (54). Then, prior to the commencement of, and every 3 weeks 149 throughout the intervention, participants were required to attend the exercise testing facility in St.

150 Columcille's Hospital on 2 separate occasions to complete a cycling ramp incremental test as well 151 as 2-4 transitions to moderate- and high-intensity cycling exercise and high-intensity calf plantar-

152 flexion exercise. In the current manuscript we report responses obtained during the cycling ramp 153 incremental tests to exhaustion. For each participant all tests were performed at the same time of 154 day. All exercise tests were carried out in an upright position on an electrically braked cycle 155 ergometer (Excalibur Sport; Lode B.V., Groningen, Netherlands). Participants were asked to 156 refrain from consuming alcohol, caffeine and non-prescribed nutritional supplements as well as 157 avoiding any strenuous exercise in the 24 hours prior to testing. At baseline (pretraining) and at 
158 the end of the intervention period (posttraining) fasting venous blood samples were collected to

159 assess glycosylated haemoglobin $\left(\mathrm{HbA}_{1 \mathrm{c}}\right)$.

160

161 Ramp incremental cycling tests: The test started with an initial workload of $10 \mathrm{~W}$ for 2 min (i.e.

162 'unloaded' cycling). This was followed by $10-25 \mathrm{~W} / \mathrm{min}$ increments in power output based on

163 participants' activity levels. Pedalling rate was held constant at an individually selected cadence

164 between 60-75 revolutions per minute (rpm) and was maintained throughout all further testing.

165 Failure in a test was determined as a drop in cadence exceeding $10 \mathrm{rpm}$ for $>5 \mathrm{~s}$. Peak workload

166 was the power output achieved at the point of failure. $\dot{\mathrm{V}} \mathrm{O}_{2 \text { peak }}$ was the highest $\dot{\mathrm{VO}}_{2}$ value (15-s

167 average) attained during the test. The first ventilatory threshold (VT) was determined by two

168 investigators as previously described (6).

169

170 Measurements

171 During exercise, participants wore a facemask to continuously collect expired air using an online

172 metabolic system (Innocor, Innovision A/S, Odense, Denmark) that measured airflow using a

173 pneumotachometer. Carbon dioxide analysis was performed by using a photoacoustic gas analyzer

174 and oxygen was analyzed using an oxygen sensor (Oxigraf Inc., USA) based on the principle of

175 laser diode absorption spectroscopy. The system was calibrated prior to each test as per

176 manufacturer's recommendations. Both the oxygen sensor and photoacoustic gas analyser require

177 multi-point calibration that is routinely performed by the manufacturer every 6-12 months.

178 Analysis of expired air allowed determination of pulmonary $\mathrm{O}_{2}$ uptake $\left(\dot{\mathrm{V}}_{2}\right), \mathrm{CO}_{2}$ output $\left(\dot{\mathrm{VCO}}_{2}\right)$,

179 minute ventilation $\left(\dot{\mathrm{V}}_{\mathrm{E}}\right)$ and the respiratory exchange ratio (RER) breath-by-breath. Heart rate 
180 (HR) was recorded every $5 \mathrm{~s}$ (Polar S610i, Polar Ltd, Finland), with peak HR defined as the highest

181 HR attained within the last $15 \mathrm{~s}$ of termination of the test.

182

183 A continuous wave NIRS system (Hamamatsu Niro 200Nx; Hamamatsu Photonics, Hamamatsu,

184 Japan), was used to determine muscle oxygenation status non-invasively through the spatially

185 resolved spectroscopy technique and modified Beer-Lambert principle, with three wavelengths of

186 emitting light $(\lambda=735,810$, and $850 \mathrm{~nm})$. The theoretical basis of NIRS and its use in exercise

187 measurements have been described in detail elsewhere (14) but briefly, this technique estimates

188 the optical density changes of oxygenated $\left(\mathrm{O}_{2} \mathrm{Hb}+\mathrm{Mb}\right)$ and deoxygenated haemoglobin and

189 myoglobin $(\mathrm{HHb}+\mathrm{Mb})$ based on the oxygen dependency of absorption changes for near-infrared

190 light in these proteins. As the vastus lateralis (VL) muscle is a dominant locomotor muscle during

191 cycling, the present study examined the $\Delta[\mathrm{HHb}+\mathrm{Mb}]$ profiles of the right $\mathrm{VL}$ muscle. After

192 shaving, cleaning and drying the skin, the probes were placed on the belly of the muscle, 10-16

$193 \mathrm{~cm}$ above the lateral femoral condyle, parallel to the major axis of the thigh with a $3 \mathrm{~cm}$ spacing

194 between the emitter and receiver. The probes were housed in a black rubber holder and secured on

195 the skin surface with bi-adhesive tape and then covered with a dark elastic bandage, which

196 minimised extraneous movement and the intrusion of stray light throughout the exercise protocol.

197 Since the depth of the measured area was estimated to be approximately one-half the distance

198 between the emitter and the receiver $(\sim 1.5 \mathrm{~cm})$, the present study determined the thickness of the

199 skin and adipose tissue at the site of the probe placement via 2D ultrasound operating in B-mode

200 (Zonare Ultra Smart Cart, Software version 4.7, USA), to ensure that data largely represented

201 absorption of near-infrared light in muscle tissue and not in subcutaneous fat. Individuals 
202 presenting with adiposity $>1.5 \mathrm{~cm}$ over the site of interrogation on the VL were excluded from the 203 study.

Data Analysis

206 Muscle deoxygenation. The NIRS-derived signal was normalised whereby the unloaded exercise 207 baseline value was adjusted to zero ('zero set'). Thus, the NIRS data are presented as a relative 208 change from the baseline- to the end-exercise values. As such $0 \%$ represents the mean steady-state 209 value of the last $30 \mathrm{~s}$ of the unloaded cycling and $100 \%$ represents the highest mean value of the 210 last $30 \mathrm{~s}$ of any work rate. This was done given the uncertainty of the optical path length in the VL 211 at rest and during exercise, so, data are presented as normalised delta units $\Delta[\mathrm{HHb}+\mathrm{Mb}]$. Prior to 212 analysis, NIRS data were averaged to give $1 \mathrm{~s}$ intervals. The second-by-second $[\mathrm{HHb}+\mathrm{Mb}]$ data 213 was averaged by applying a five-point moving average and then normalised to the peak amplitude 214 of the response $(\% \Delta[\mathrm{HHb}+\mathrm{Mb}])$. The $[\mathrm{HHb}+\mathrm{Mb}]$ response dynamics were expressed in relation 215 to relative power output (\%PO) prior to curve fitting. Therefore, individual profiles were plotted 216 as a function of $\% \mathrm{PO}$ and characterised by a linear function with two terms to establish the slope 217 of increase of deoxygenation (slope $)_{1}$, plateau as maximal exercise was approached (slope 2 ), and 218 the break point $(B P)$ located between the increasing deoxygenation and its plateau. The double 219 linear function was applied using TableCurve 2D (Systat Software, USA) as:

220

$221 y=a+b * x-c *(x-d) * f$

222

223

$f=$ if $(x<d, 0,1)$ 
224 where $a$ and $b$ represent the y-intercept and slope of the first linear function (slope 1 ), $d$ is the time

225 delay or break point $(B P)$ where the segments intersect, with the slope of the second linear function

$226\left(\right.$ slope $\left._{2}\right)$ being calculated from the parameter estimates of $b$ and $c\left(\right.$ slope $\left._{2}=b-c\right)$.

227

$228 \Delta \dot{V} O_{2} / \Delta P O$

229 The rate of change of $\dot{\mathrm{VO}}_{2}$ relative to PO during ramp incremental exercise reflects the capacity 230 of aerobic metabolism to adjust to the non-steady state conditions incurred during a ramp

231 incremental protocol. Initially, the mean response time (MRT) of $\dot{\mathrm{V}}_{2}$ during the ramp incremental

232 exercise was estimated using the approach recently described by Iannetta et al. (23). Briefly, we

233 determined the average steady-state $\dot{\mathrm{VO}}_{2}$ corresponding to 2-3 separate bouts of moderate-

234 intensity constant-power outputs (performed on a separate visit), and we then compared the ramp-

235 derived power output associated with that $\mathrm{V}_{2}$ to the constant-power output which elicited that

$236 \dot{\mathrm{V}} \mathrm{O}_{2}$. The difference between these power outputs was then converted to the time (taking into 237 account the slope of the ramp protocol) to retrieve the time-interval corresponding to MRT. The 238 breath by breath $\mathrm{V}_{2}$ data were averaged over $15 \mathrm{~s}$ intervals and plotted as a function of work rate 239 after accounting for the MRT to reflect the increase in aerobic metabolism $\left(\Delta \dot{\mathrm{V}} \mathrm{O}_{2}\right)$ for each 240 increase in power output $(\Delta \mathrm{PO})$. From this the $\Delta \dot{\mathrm{V}} \mathrm{O}_{2} / \Delta \mathrm{PO}$ slope was calculated over the same 241 range of $\mathrm{PO}$ as used to determine the first $\% \Delta[\mathrm{HHb}+\mathrm{Mb}] / \% \mathrm{PO}$ slope (i.e parameter $b$ or slope ${ }_{1}$ ) 242 as described above.

244 Statistical Analysis

245 Physical characteristics and activity levels at baseline among groups were compared using a one246 way ANOVA. Peak physiological responses and NIRS-derived muscle deoxygenation responses 
247 during the intervention were compared using a two-factor [time (pretraining, week 3, week 6, week

248 9, posttraining) vs. group (HIIT, MICT, Control)] mixed ANOVA. Body mass and $\mathrm{HbA}_{1 \mathrm{c}}$ results 249 were also compared using a two-factor [time (pretraining, posttraining) vs. group (HIIT, MICT, 250 Control)] mixed ANOVA. Differences were detected using a Student-Newman-Keuls post hoc 251 test. Correlations between pretraining $\dot{\mathrm{V}}_{2 \text { peak }}$ or \% change in slope 1 with the percentage change 252 in $\dot{\mathrm{V}} \mathrm{O}_{2 \text { peak }}$ were established using the Pearson product-moment correlation coefficient (Pearson $253 r$ ). A power analysis indicated that eight participants per group were required to detect a $\sim 16 \%$ 254 improvement in $\dot{\mathrm{V}}_{2 \text { peak }}$ with a power of 0.80 and alpha of 0.05 for an ANOVA calculation design 255 based on 3 groups. This was estimated using means and standard deviations from previously 256 published data on participants with similar baseline physical characteristics and activity levels as 257 in the current study following short term HIIT and MICT interventions (21, 34, 67). Significance 258 was set at $P<0.05$. All values are expressed as mean \pm standard deviation (SD).

\section{Results}

261 Physical characteristics and activity levels.

262 Participants' physical characteristics at baseline are presented in Table 1. All three groups were 263 well matched according to age, time since diabetes diagnosis, body mass, body mass index, $\mathrm{HbA}_{1 \mathrm{c}}$ 264 and activity levels. There was a significant time $\mathrm{x}$ group interaction $(P<0.001)$ for body mass so 265 that posttraining body mass was reduced $(P=0.001)$ in the MICT group (pre $=92.1 \pm 20.6 \mathrm{~kg}$, 266 post $=89.7 \pm 20.1 \mathrm{~kg}$ ) but not in the HIIT (pre $=87.5 \pm 12.4 \mathrm{~kg}$, post $=86.5 \pm 12.2 \mathrm{~kg}$ ) or control $267 \quad($ pre $=86.0 \pm 14.0 \mathrm{~kg}$, post $=86.4 \pm 15.6 \mathrm{~kg})$ groups. $\mathrm{HbA}_{1 \mathrm{c}}(\%)($ time $\mathrm{x}$ group interaction, $P<$ $2680.001)$ was reduced in the MICT (pre $=6.8 \pm 0.5 \%$, post $=6.6 \pm 0.5 \%)$ and HIIT groups ( pre $=7.3$ $269 \pm 0.5 \%$, post $=7.0 \pm 0.6 \%$ ) but not in the control (pre $=6.8 \pm 1.0 \%$, post $=7.0 \pm 1.0 \%$ ) group 
Exercise adherence and work done

272 The mean exercise adherence was $94 \pm 6 \%$ (range 31-36 sessions) and $96 \pm 6 \%$ (range 31-36

273 sessions) in the HIIT and MICT groups respectively. The average training intensity (PO) increased 274 significantly $(P<0.05)$ after each testing session (i.e., every 3 weeks) in the MICT group (weeks $2751-3,82 \pm 32 \mathrm{~W}$; weeks 4-6, $100 \pm 39 \mathrm{~W}$; weeks 7-9, $110 \pm 42 \mathrm{~W}$; weeks 10-12, $119 \pm 44 \mathrm{~W})$ 276 while it also significantly increased every 3 weeks until week 9, but not between week 9 and 12 277 $(P=0.24)$ in the HIIT group (weeks $1-3,166 \pm 45 \mathrm{~W}$; weeks 4-6, $181 \pm 46 \mathrm{~W}$; weeks 7-9, $193 \pm$ $46 \mathrm{~W}$; weeks 10-12, $197 \pm 45 \mathrm{~W}$ ). The average total work done per training session (including the warm up) was $\sim 165 \mathrm{~kJ}$ for the HIIT and $\sim 326 \mathrm{~kJ}$ for the MICT groups. No adverse training effects 280 were observed throughout the intervention period in either exercising group.

\section{Peak physiological responses during ramp exercise}

283 Peak physiological responses throughout the training period are summarised in Table 2, while 284 individual $\dot{\mathrm{V}} \mathrm{O}_{2 \text { peak }}\left(\mathrm{ml}_{\mathrm{kg}} \mathrm{kg}^{-1} \cdot \mathrm{min}^{-1}\right)$ responses are shown in Fig 2. For absolute $\dot{\mathrm{V}} \mathrm{O}_{2 \text { peak }}$ as well as $285 \dot{\mathrm{V}} \mathrm{O}_{2 \text { peak }}$ normalised to body mass, there was a significant time $\mathrm{x}$ group interaction $(P<0.001$, 286 statistical power $=0.84$ and 0.99 respectively), so that $\dot{\mathrm{VO}_{2} \text { peak }}$ did not increase in the control group, 287 but it significantly increased after 3 weeks of MICT and HIIT, with no further significant changes 288 thereafter. The percentage change in $\dot{\mathrm{V}} \mathrm{O}_{2 \text { peak }}\left(\mathrm{ml} \cdot \mathrm{kg}^{-1} \cdot \mathrm{min}^{-1}\right)$ from pretraining to posttraining was 289 not significantly different in the MICT $(27 \pm 21 \%)$ and HIIT $(14 \pm 8 \%)$ groups $(P=0.14)$, but it 290 was larger from pretraining to week 6 in the MICT $(25 \pm 12 \%)$ than the HIIT $(11 \pm 8 \%)$ group $(P$ $291<0.01$ ). The percentage changes in $\dot{\mathrm{V}} \mathrm{O}_{2 \text { peak }}$ (relative to both, pretraining and posttraining) are 292 illustrated in Fig 3. Importantly, pretraining $\dot{\mathrm{V}} \mathrm{O}_{2 \text { peak }}$ was significantly correlated with the 
293 percentage change in $\dot{\mathrm{V}}_{\text {2peak }}$ among exercising participants $(\mathrm{r}=52, P=0.02)(\mathrm{Fig} 4) . \mathrm{HR}_{\max }$ did 294 not change from pre- to post-intervention in any of the groups. Consequently, peak $\mathrm{O}_{2}$ pulse 295 significantly increased after 3 weeks of MICT and HIIT with no further changes thereafter, while 296 it did not change in the control group (time $\mathrm{x}$ group interaction, $P<0.01$ ). In addition, $\mathrm{PO}_{\text {peak }}$ was 297 higher at week 3 than pretraining in both the HIIT and MICT groups. Further changes in PO $_{\text {peak }}$ 298 were observed in the MICT group from week 6 to 9 and from week 9 to posttraining; whereas in 299 the HIIT group $\mathrm{PO}_{\text {peak }}$ further increased from week 3 to 6 . PO at VT was significantly increased 300 at week 3, and between week 3 and 6 in both exercising groups. In contrast, $\mathrm{PO}_{\text {peak }}$ or PO at VT 301 was not changed throughout the 12 week period in the control group. There was a main effect of 302 group $(P<0.01)$ for RER values so that they were larger in the HIIT compared with the other 2 303 groups. Finally, there was a main effect of time $(P<0.05)$ for $\dot{\mathrm{V}} \mathrm{CO}_{2 \text { peak, }} \dot{\mathrm{V}} \mathrm{E}_{\text {peak }}$ and MRT without 304 with pretraining.

\section{Muscle deoxygenation $[\mathrm{HHb}+\mathrm{Mb}]$ responses during ramp exercise}

309 Group mean parameter estimates from the double linear model of the $\Delta[\mathrm{HHb}+\mathrm{Mb}]$ profile as a

310 function of normalised power output (\%PO) are summarised in Table 3. Individual representative

311 profiles of the modelled $[\mathrm{HHb}+\mathrm{Mb}]$ response dynamics as a function of $\% \mathrm{PO}$ are displayed in Fig

312 5. Due to a technical error with the NIRS data, results from 4 participants ( 2 participants from the

313 MICT and 2 from the control group) were excluded from the analyses. There was a significant

314 time $\mathrm{x}$ group interaction $(P=0.04)$ for the slope of the first linear regression function (slope 1 ) used

315 to establish the dynamic adjustment of $[\mathrm{HHb}+\mathrm{Mb}]$. In both exercising groups slope $\mathrm{I}_{1}$ was 
316 significantly reduced at week 3 with no further changes observed thereafter; whereas no changes

317 in slope ${ }_{1}$ were observed in the control group. The percentage change in slope ${ }_{1}$ from pretraining to

318 posttraining was not significantly different in the MICT and HIIT groups. The percentage changes

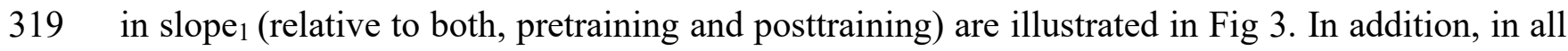

320 participants, the percentage change in slope ${ }_{1}$ was significantly correlated with the percentage

321 change in $\dot{\mathrm{V}}_{2 \text { peak }}$ at week $3(\mathrm{r}=-0.51, P<0.01)$, week $6(\mathrm{r}=-0.41, P=0.03)$ and posttraining $(\mathrm{r}$

$322=-0.40, P=0.04)$ but not at week $9(\mathrm{r}=-0.25, P=0.21)$. However, within each group or among

323 the 2 exercising groups together, the percentage change in slope $e_{1}$ was not significantly correlated

324 with the percentage change in $\dot{\mathrm{V}}_{2 \text { peak }}$ at any time point. The slope of the second $\Delta[\mathrm{HHb}+\mathrm{Mb}] /$

$325 \% \mathrm{PO}$ regression function ( slope $\left._{2}\right)$ and the break point $\left(\% \mathrm{PO}_{\text {peak }}\right)$ did not change throughout the 12

326 week period in any of the groups.

327

$328 \Delta \dot{V} \mathrm{O}_{2} / \triangle \mathrm{PO}$

329 The rate of change in $\dot{\mathrm{V}}_{2} / \mathrm{PO}$ during the ramp incremental test was not significantly different

330 between groups or among groups throughout the 12 week period of the intervention (Table 2).

331

\section{Discussion}

333 To our knowledge this is the first study to explore the time-course effects of low-volume HIIT and

334 MICT interventions on $\dot{\mathrm{V}}_{2 \text { peak }}$ and muscle deoxygenation responses during a ramp incremental

335 exercise test in uncomplicated T2D. The main findings were that both HIIT and MICT

336 significantly improved $\dot{\mathrm{V}}_{2 \text { peak }}$ by week 3 of the intervention and that these effects were likely

337 linked to improvements in microvascular $\mathrm{O}_{2}$ delivery, as suggested by the less steep slope in the

$338 \mathrm{O}_{2}$ extraction signal during the ramp incremental test. These benefits in $\dot{\mathrm{V}}_{2 \text { peak }}$ and muscle 
339 deoxygenation followed a time course that was not different between groups and were maintained

340 for the remainder of both exercise interventions without further improvement. This rapid

341 improvement in cardiorespiratory fitness is of great clinical relevance, as it significantly reduces

342 the risk for adverse cardiovascular outcomes and all-cause mortality (53).

344 In the present study a single incremental exercise test was performed at each time point. While 345 performing an additional incremental test and/or verification ride at each time point would have

346 been benefitial to add confidence in the outcome, the training-induced significant increases in peak

$347 \mathrm{O}_{2}$ pulse suggest that the training response following MICT and HIIT was captured as opposed to 348 participants providing more effort as they became more used to exercise.

350 Time-course effects on $\dot{V} O_{2 p e a k}$

351 After the 12-week intervention, in the present study both MICT and HIIT significantly increased $352 \mathrm{~V}_{2 \text { peak }}$ by $27 \%$ and $14 \%$ respectively. Such improvements are in keeping with the literature 353 pertaining to short-term exercise training in individuals with uncomplicated T2D subsequent to 354 MICT $(10,21,31)$ and low-volume $\operatorname{HITT}(15,34,51,67)$. The tendency for the overall larger 355 percentage increase in $\dot{\mathrm{V}}_{2 \text { peak }}$ herein for the MICT group (27\% vs $\left.14 \%, P=0.14\right)$ can partly be 356 attributed to the $\sim 16 \%$ lower initial baseline $\dot{\mathrm{V}} \mathrm{O}_{2 \text { peak }}$ of the MICT group, despite random 357 assignment, given that pretraining $\dot{\mathrm{V}}_{2 \text { peak }}$ was significantly correlated to the percentage increase 358 in $\mathrm{V}_{2 \text { peak }}$ in both training groups. Our findings are consistent with those from a recent multi359 centre comparative study (across 18 studies) of $\dot{\mathrm{V}} \mathrm{O}_{2 \text { peak }}$ trainability between interval and 360 continuous training modalities in both healthy $(n=272)$ and clinical populations $(n=405)$ where 361 no significant differences were revealed between MICT and low-volume HIIT in $\mathrm{V}_{2 \text { peak }}(66)$. 
362 Only a small number of previous studies compared the effects of HIIT and MICT on $\dot{\mathrm{V}} \mathrm{O}_{2 \text { peak }}$ in

363 individuals with uncomplicated T2D $(37,60,70)$ and results are equivocal. For instance, Winding

364 et al. (70) reported a $20 \%$ increase in $\dot{\mathrm{VO}} 2$ peak after 11 weeks of HIIT $(10$ x 60 s cycling at $95 \%$

$365 \mathrm{PO}_{\text {peak }}$ ) which was greater than the $8 \%$ increase in $\mathrm{V}_{2 \text { peak }}$ observed after MICT (8\% increase; 40

366 mins cycling at 50\% $\mathrm{PO}_{\text {peak }}$ ). Similarly, Mitranun et al. (37) reported a $25 \%$ increase in $\dot{\mathrm{V}} \mathrm{O}_{2 \max }$

367 following 12 weeks of HIIT (4-6 x 1 minute intervals at 80-85\% $\dot{\mathrm{VO}}_{2 \max }$ with 4 min active recovery

368 at $50-60 \% \dot{\mathrm{VO}_{2 \max }}$ ) compared to a $14 \%$ increase after $\mathrm{MICT}\left(20-30 \mathrm{~min}\right.$ at $\left.60-65 \% \dot{\mathrm{VO}}_{2 \max }\right)$;

369 however, the 2 interventions therein were matched for exercise energy expenditure, resulting in a

370 similar time commitment (HIIT: 26 mins vs MICT: 30 mins), thereby countering the time efficacy

371 attraction of HIIT. On the contrary, also employing energy-matched HIIT and MICT interventions,

372 Terada et al. (60) did not observe significant benefits in $\mathrm{V}_{2 \text { peak }}$ subsequent to 12 weeks of training

373 in either group. It is likely that differences in the age range, initial fitness and physical activity

374 levels, or the duration and severity of diabetes among participants in the different studies as well

375 as differences in study protocols are factors that likely contributed to the response variation

376 following these training modalities.

377

378 A novel and clinically relevant finding herein is that $\mathrm{V}_{2 \text { peak }}$ increased within 3 weeks of training

379 in both the MICT and HIIT groups (17\% and $8 \%$ respectively), accounting for $\sim 60 \%$ of the total

380 change in $\dot{\mathrm{VO}}_{2 \text { peak }}$ in both groups. Despite an additional 10\% and $6 \%$ numerical increase between

381 week 3 and posttraining following MICT and HIIT respectively, no further significant changes

382 were observed in any of the training groups. It is likely that interindividual variability in response

383 precluded these increases to attain statistical significance. A levelling off in the increase in $\dot{\mathrm{V}} \mathrm{O}_{2 \text { peak, }}$

384 despite an adjustment in intensity, has also been reported in healthy individuals during short-term 
385 low-volume HIIT interventions $(1,2)$. Interestingly, Astorino et al. (1) showed that subsequent to

38610 low-volume HIIT sessions ( $8-10 \times 60 \mathrm{~s}$ cycling at $\left.90-100 \% \mathrm{PO}_{\text {peak }}\right), 10$ additional sprint interval

387 training sessions (8-12 "all-out" $30 \mathrm{~s}$ sprints) further increased $\mathrm{V}_{2 \max }$ in young active individuals,

388 whereas 10 additional high-volume HIIT sessions (5-7 x 150 s cycling at $\left.70-80 \% \mathrm{PO}_{\text {peak }}\right)$ did not.

389 The findings by Astorino and colleagues (1) suggest that in order to further increase $\dot{\mathrm{V}}_{2 \max }$

390 beyond the initial few weeks of training, a modification in the structure, rather than volume, of the

391 HIIT sessions might be needed. Among studies investigating time course of effects on

392 cardiorespiratory fitness in healthy individuals following short-term aerobic continuous training

393 interventions mixed results have been reported. When training intensities $\geq 70 \% \dot{\mathrm{V}}_{2 \max }$ were

394 employed, studies showed progressive linear increases in $\dot{\mathrm{V}}_{2 \max }(22,38,40)$, no changes until

395 posttraining (17) or changes at posttraining in additions to changes at one additional time point

396 (41, 63); whereas employing lower training intensities $\left(50-60 \% \dot{\mathrm{V}}_{2 \max }\right)$ a plateau beyond the mid-

397 point of the training interventions has been reported $(16,44)$. It should be noted that only one of

398 these interventions employed training intensities relative to 'metabolic thresholds' (63) but therein,

399 exercise training intensity progressed from moderate-intensity $(<\mathrm{VT})$ to severe-intensity $(>\mathrm{VT} 2)$

400 throughout the intervention.

401

402 Muscle deoxygenation responses

403 In order to explore if peripheral microvascular function affected the changes in $\dot{\mathrm{V}}_{2 \text { peak }}$ in $\mathrm{T} 2 \mathrm{D}$

404 following both training interventions, the present study investigated the rates of NIRS-derived

405 fractional $\mathrm{O}_{2}$ extraction within the vastus lateralis. The profile of $\% \Delta[\mathrm{HHb}+\mathrm{Mb}]$, characterised

406 by a 'double-linear model' (62) offers an insight into the dynamic balance between regional

407 oxygen delivery and $\dot{\mathrm{VO}}_{2}$ at the level of the microvasculature (57). In the first segment therein, a 
408 linear increase in $\% \Delta[\mathrm{HHb}+\mathrm{Mb}]$ relative to changes in work rate occurs, representing the 409 increasing reliance on $\mathrm{O}_{2}$ extraction relative to metabolic demand, which culminates at a 410 'breakpoint' $(\Delta[\mathrm{HHb}+\mathrm{Mb}]-B P)$, from which a "plateau-like" response ensues despite the 411 continued increase in work rate. That the initial slope of this first linear increase in $\% \Delta[\mathrm{HHb}+\mathrm{Mb}]$

412 herein was significantly reduced in both training groups after 3 weeks with no further significant

413 changes thereafter, while the rate of increase in $\dot{\mathrm{V}} \mathrm{O}_{2}$ relative to $\mathrm{PO}$ (i.e. $\Delta \dot{\mathrm{V}} \mathrm{O}_{2} / \Delta \mathrm{PO}$ ) remained 414 unchanged, suggests that exercise-induced improvements in microvascular $\mathrm{O}_{2}$ delivery 415 contributed, at least partly, to reducing the dependence on fractional $\mathrm{O}_{2}$ extraction during ramp 416 exercise. Additionally, the training-induced reductions in the $\mathrm{MRT}$ of the $\mathrm{V}_{2}$ response during the 417 ramp tests observed herein may also suggest an enhanced muscle oxidative capacity, given that 418 cardiorespiratory fitness has been shown to be associated with this parameter (36), and are 419 consistent with reductions observed in individuals with a prior myocardial infarction following a 420 short-term MICT intervention (59). That the reductions in MRT were not significantly different 421 until week 9 despite a numerical reduction from week 3 onwards can likely be attributed to the 422 large variation in MRT responses herein. This large variation was influenced, at least partly, by 423 the different ramp slopes utilized by participants in the present study (9).

425 Indeed an impaired peripheral $\mathrm{O}_{2}$ delivery extant during maximal exercise in this clinical 426 population has been documented. Specifically reductions in maximum leg haemodynamic and 427 vasodilatory responses during an incremental calf plantar-flexion exercise (26) as well as 428 alterations in the profile of muscle fractional $\mathrm{O}_{2}$ extraction at the interface of the capillary to 429 myocyte within the vastus lateralis muscle in individuals with uncomplicated T2D during ramp 430 incremental cycle exercise (18) have been reported. Therein, Gildea et al. (18) observed that T2D 
431 induced a greater reliance on NIRS-derived $\mathrm{O}_{2}$ extraction for a given PO compared with healthy

432 controls despite a similar rate of increase in $\dot{\mathrm{V}}_{2}$ relative to $\mathrm{PO}$ (i.e. $\Delta \dot{\mathrm{V}} \mathrm{O}_{2} / \Delta \mathrm{PO}$ ). Similarly, in

433 rodent models with $\mathrm{T} 2 \mathrm{D}$, greater microvascular deoxygenation responses at any given absolute

434 PO were observed compared with controls (7), which were associated with a lower oxygen

435 delivery and $\dot{\mathrm{VO}}_{2}$ at the level of the microvasculature, the determining factor for microvascular

436 partial pressure of $\mathrm{O}_{2}$ and thereby, lower $\mathrm{O}_{2}$ diffusion to the muscle mitochondria (7).

438 In the present study the $\mathrm{BP}$ (as \% $\mathrm{PO}_{\text {peak }}$ ) did not change throughout the intervention even if the 439 slope of muscle deoxygenation (slope ${ }_{1}$ ) was reduced. The fact that the onset of slope $e_{1}$ did not occur

440 at the same time point (relative to $\% \mathrm{PO}_{\text {peak }}$ ) between or within participants throughout the 441 intervention (see representative responses in the MICT and HIIT groups in Fig 5) likely influenced 442 this.

444 Although the mechanisms responsible for the enhanced profile of muscle fractional $\mathrm{O}_{2}$ extraction 445

446 in vascular function likely contributed to the early improvements given that functional endothelial 447 improvements have been elicited within as little as 2 weeks of MICT and resistance training in 448 T2D (56). Other mechanisms potentially at play, include structural adaptations within the 449 vasculature $(12,33)$ and increased capillary-to-myocyte interface for tissue perfusion and substrate 450 delivery (39), potentially by increasing the proportion of red blood cell-flowing capillaries in 451 muscle which is reduced in T2D, at least in rats (47). However, these structural adaptations have 452 been reported beyond 8 weeks of training, so, it is likely that they influenced the non-significant 453 changes observed in the latter part of the interventions and/or helped maintain the early 
454 adaptations. On the other hand, in addition to the enhanced peripheral adaptations observed herein,

455 it is possible that central adaptations (i.e. peak stroke volume and cardiac output) also influenced

456 the increases in $\dot{\mathrm{V}}_{2 \text { peak. }}$. For instance, recent evidence suggests that short-term HIIT increases left

457 ventricular stroke volume via increases in left ventricular end-diastolic volume, during

458 submaximal exercise intensities in uncomplicated T2D and that these effects are independent of

459 changes in total blood volume (67). On the other hand, in healthy untrained older men, peak

460 cardiac output (and stroke volume) responses were increased, accompanied with simultaneous

461 increases in $\dot{\mathrm{V}}_{2 \max }$, within 3 weeks of a 12 -week MICT intervention (41). Further studies are

462 needed to elucidate the time-course of effects on central adaptations following training in T2D and

463 how these adaptations influence changes in cardiorespiratory fitness.

465 Limitations

466 A number of limitations of the present study must be acknowledged. First, even if in the present 467 study mixed groups of men and women were included in each study arm, sex-related effects on 468 the magnitude of responses to HIIT and MICT in T2D are likely small given that 12-weeks of 469 MICT in individuals with T2D (21), as well as 6 weeks of HIIT in individuals with risk factors for 470 T2D (48), showed no difference in response between men and women. Second, we also 471 acknowledge that the muscle deoxygenation findings herein relate to the evaluation of a single 472 muscle, the VL. Therefore, interpretation of this data is limited to the examined region, with 473 potential structural (vascularity and fibre type) (24), and functional (fibre recruitment, vascular 474 control and blood flow $(8,29,35)$ differences acknowledged. In addition, NIRS signals have 475 temporal and spatial heterogeneity among muscles and within deep and superficial muscle 476 segments $(28,45,55)$ which likely extend to the vastus lateralis herein. Third, we did not take into 
477 account the MRT of the $\dot{\mathrm{VO}}_{2}$ during the ramp incremental tests when calculating the exercise 478 training intensities, and hence, power outputs corresponding to the VT may have been slightly 479 overestimated. This is particularly relevant for the MICT group who trained at an intensity close 480 to VT (i.e. $~ 80-90 \%$ VT). Despite this, $\mathrm{V}_{2}$ kinetics analyses carried out at $80 \%$ VT on a separate 481 visit (data not shown) revealed that only 2 participants of the MICT group demonstrated a small $482 \dot{\mathrm{VO}}_{2}$ 'slow component', hence, the majority of participants in the MICT group likely exercised 483 activity levels. However, baseline $\dot{\mathrm{V}} \mathrm{O}_{2 \text { peak }}$ values expressed as $\mathrm{ml} \cdot \mathrm{kg}^{-1} \cdot \mathrm{min}^{-1}$ (although not $\dot{\mathrm{V}}_{2 \text { peak }}$ values expressed as $\mathrm{L} / \mathrm{min}$ or $\mathrm{PO}_{\text {peak }}$ values) were indeed higher $(P<0.05$, one-way ANOVA) in the HIIT compared with the other groups, and given that these values influenced the training488 induced changes in $\dot{\mathrm{V}}_{2 \text { peak }}$ in our exercising participants (Fig 4), baseline $\dot{\mathrm{V}} \mathrm{O}_{2 \text { peak }}$ values among groups should therefore be controlled in future studies.

\section{Perspective and significance}

492 Exercise adherence in individuals with T2D is low, with lack of time and fear of having an acute 493 adverse health event often cited as barriers for not being more active. In addition, those living with 494 T2D consistently demonstrate a decreased cardiorespiratory fitness or exercise tolerance which is 495 an independent prognostic marker for mortality. In the present study the time-efficient HIIT in 496 parity with MICT achieved rapid (i.e. within 3 weeks) clinically significant benefits in 497 cardiorespiratory fitness which were accompanied with simultaneous reductions in fractional $\mathrm{O}_{2}$ 498 extraction of the active musculature. This suggests that augmenting the initial diminished capacity 499 to increase peripheral $\mathrm{O}_{2}$ delivery to meet the increasing $\mathrm{O}_{2}$ demands during exercise, serves to 
500 positively impact muscle oxidative metabolism and thus, exercise tolerance in uncomplicated

501 T2D. Importantly, the training volume and time commitment herein was $\sim 50 \%$ lower in the HIIT

502 compared with the MICT group, while no adverse events were reported. Thus, physicians and 503 exercise practitioners should consider low-volume HIIT as an attractive exercise modality that 504 could be better suited to the time availability and motivational level of novice exercisers with T2D. 505

\section{Grants}

507 This publication has emanated from research conducted with the financial support of the Health 508 Research Board (Grant No 08/RFP/BMT1342).

509

510 Disclosures

511 No conflicts of interest, financial or otherwise, are declared by the authors.

512

\section{Author contributions}

514 N.G., A.M'D., J.R., M.E., D.O'S. and S.G. conception and design of research; N.G., A.M'D. and 515 J.R. performed experiments; N.G., A.M'D. and M.E. analyzed data; N.G., J.R., A.M'D., S.G. and

516 M.E. interpreted results of experiments; N.G. and M.E. prepared figures; N.G. and M.E. drafted 517 manuscript; N.G., A.M'D., J.R., D.O'S., S.G. and M.E. edited and revised manuscript; N.G., 518 A.M'D., J.R., D.O’S., S.G. and M.E. approved final version of manuscript. 
521 1. Astorino TA, Edmunds RM, Clark A, King L, Gallant RA, Namm S, Fischer A, and

522

523

524

525

526

527

528

529

530

531

532

533

534

535

536

537

538

539

540

541

542

543

544

545

546

547

548

549

550

551

552

553

554

555

556

557

558

559

560

561

562

563

Wood KM. High-Intensity Interval Training Increases Cardiac Output and V'O2max. Med Sci Sports Exerc 49: 265-273, 2017.

2. Astorino TA, Schubert MM, Palumbo E, Stirling D, McMillan DW, Cooper C, Godinez J, Martinez D, and Gallant R. Magnitude and time course of changes in maximal oxygen uptake in response to distinct regimens of chronic interval training in sedentary women. Eur J Appl Physiol 113: 2361-2369, 2013.

3. Baldi JC, Aoina JL, Oxenham HC, Bagg W, and Doughty RN. Reduced exercise arteriovenous O2 difference in Type 2 diabetes. J Appl Physiol 94: 1033-1038, 2003.

4. Balducci S, Sacchetti M, Haxhi J, Orlando G, Zanuso S, Cardelli P, Cavallo S, D'Errico V, Ribaudo MC, Di Biase N, Salvi L, Vitale M, Bollanti L, Conti FG, Nicolucci A, and Pugliese G. The Italian Diabetes and Exercise Study 2 (IDES-2): a long-term behavioral intervention for adoption and maintenance of a physically active lifestyle. Trials 16: 569, 2015.

5. Bauer TA, Reusch JEB, Levi M, and Regensteiner JG. Skeletal muscle deoxygenation after the onset of moderate exercise suggests slowed microvascular blood flow kinetics in type 2 diabetes. Diabetes Care 30: 2880-2885, 2007.

6. Beaver WL, Wasserman K, and Whipp BJ. A new method for detecting anaerobic threshold by gas exchange. J Appl Physiol 60: 2020-2027, 1986.

7. Behnke BJ, Kindig CA, McDonough P, Poole DC, and Sexton WL. Dynamics of microvascular oxygen pressure during rest-contraction transition in skeletal muscle of diabetic rats. Am J Physiol Heart Circ Physiol 283: H926-932, 2002.

8. Behnke BJ, McDonough P, Padilla DJ, Musch TI, and Poole DC. Oxygen exchange profile in rat muscles of contrasting fibre types. $J$ Physiol 549: 597-605, 2003.

9. Boone J, and Bourgois $\mathbf{J}$. The oxygen uptake response to incremental ramp exercise: methodogical and physiological issues. Sports Med 42: 511-526, 2012.

10. Brandenburg SL, Reusch JE, Bauer TA, Jeffers BW, Hiatt WR, and Regensteiner JG. Effects of exercise training on oxygen uptake kinetic responses in women with type 2 diabetes. Diabetes Care 22: 1640-1646, 1999.

11. Colberg SR, Sigal RJ, Yardley JE, Riddell MC, Dunstan DW, Dempsey PC, Horton ES, Castorino K, and Tate DF. Physical Activity/Exercise and Diabetes: A Position Statement of the American Diabetes Association. Diabetes Care 39: 2065-2079, 2016.

12. da Silva CA, Ribeiro JP, Canto JC, da Silva RE, Silva Junior GB, Botura E, and Malschitzky MA. High-intensity aerobic training improves endothelium-dependent vasodilation in patients with metabolic syndrome and type 2 diabetes mellitus. Diabetes Res Clin Pract 95: 237-245, 2012.

13. Dagogo-Jack $\mathbf{S}$. Preventing diabetes-related morbidity and mortality in the primary care setting. J Natl Med Assoc 94: 549-560, 2002.

14. Ferrari M, Muthalib M, and Quaresima V. The use of near-infrared spectroscopy in understanding skeletal muscle physiology: recent developments. Philos Trans A Math Phys Eng Sci 369: 4577-4590, 2011.

15. Francois ME, Pistawka KJ, Halperin FA, and Little JP. Cardiovascular benefits of combined interval training and post-exercise nutrition in type 2 diabetes. J Diabetes Complications 2017. 
564 16. Gaesser GA, and Rich RG. Effects of high- and low-intensity exercise training on aerobic 565 capacity and blood lipids. Med Sci Sports Exerc 16: 269-274, 1984.

566 17. Gass G, Gass E, Wicks J, Browning J, Bennett G, and Morris N. Rate and amplitude 567 of adaptation to two intensities of exercise in men aged 65-75 yr. Med Sci Sports Exerc 36: 1811$5681818,2004$.

569 18. Gildea N, Rocha J, McDermott A, O'Shea D, Green S, and Egaña M. Influence of type 5702 diabetes on muscle deoxygenation during ramp incremental cycle exercise. Respir Physiol $571 \quad$ Neurobiol 269: 103258, 2019.

572 19. Gildea N, Rocha J, O'Shea D, Green S, and Egaña M. Priming exercise accelerates 573 pulmonary oxygen uptake kinetics during "work-to-work" cycle exercise in middle-aged individuals with type 2 diabetes. Eur J Appl Physiol 2020.

20. Green S, Egana M, Baldi JC, Lamberts R, and Regensteiner JG. Cardiovascular control during exercise in type 2 diabetes mellitus. J Diabetes Res 2015: 654204, 2015.

21. Green S, Kiely C, O'Connor E, Gildea N, O'Shea D, and Egaña M. Effects of exercise training and sex on dynamic responses of $\mathrm{O} 2$ uptake in type 2 diabetes. Appl Physiol Nutr Metab 2020.

22. Hickson RC, Bomze HA, and Holloszy JO. Linear increase in aerobic power induced by a strenuous program of endurance exercise. J Appl Physiol Respir Environ Exerc Physiol 42: 372$376,1977$.

23. Iannetta D, Murias JM, and Keir DA. A Simple Method to Quantify the V O2 Mean Response Time of Ramp-Incremental Exercise. Med Sci Sports Exerc 51: 1080-1086, 2019.

24. Johnson MA, Polgar J, Weightman D, and Appleton D. Data on the distribution of fibre types in thirty-six human muscles. An autopsy study. J Neurol Sci 18: 111-129, 1973.

25. Kiely C, O'Connor E, O'Shea D, Green S, and Egana M. Hemodynamic responses during graded and constant-load plantar flexion exercise in middle-aged men and women with type 2 diabetes. Journal of Applied Physiology 117: 755-764, 2014.

590 26. Kiely C, O'Connor E, O'Shea D, Green S, and Egaña M. Hemodynamic responses during graded and constant-load plantar flexion exercise in middle-aged men and women with type 2 diabetes. J Appl Physiol (1985) 117: 755-764, 2014. 27. Kingwell BA, Formosa M, Muhlmann M, Bradley SJ, and McConnell GK. Type 2 diabetic individuals have impaired leg blood flow responses to exercise. Diabetes Care 26: 899904, 2003.

28. Koga S, Poole DC, Ferreira LF, Whipp BJ, Kondo N, Saitoh T, Ohmae E, and Barstow TJ. Spatial heterogeneity of quadriceps muscle deoxygenation kinetics during cycle exercise. J Appl Physiol (1985) 103: 2049-2056, 2007. 29. Koga S, Poole DC, Fukuoka Y, Ferreira LF, Kondo N, Ohmae E, and Barstow TJ. Methodological validation of the dynamic heterogeneity of muscle deoxygenation within the quadriceps during cycle exercise. Am J Physiol Regul Integr Comp Physiol 301: R534-541, 2011. 30. Mac Ananey O, Malone J, Warmington S, O'Shea D, Green S, and Egaña M. Cardiac output is not related to the slowed o2 uptake kinetics in type 2 diabetes. Med Sci Sports Exerc 43: 935-942, 2011.

605

606

607

31. Macananey O, O'Shea D, Warmington SA, Green S, and Egaña M. Gymnasium-based unsupervised exercise maintains benefits in oxygen uptake kinetics obtained following supervised training in type 2 diabetes. Appl Physiol Nutr Metab 37: 599-609, 2012. 
32. MacAnaney $\mathbf{O}$, Reilly H, O'Shea D, Egana M, and Green S. Effect of type 2 diabetes on the dynamic response characteristics of leg vascular conductance during exercise. Diabetes and Vascular Disease Research 8: 12-21, 2011.

33. Madsen SM, Thorup AC, Overgaard K, Bjerre M, and Jeppesen PB. Functional and structural vascular adaptations following 8 weeks of low volume high intensity interval training in lower leg of type 2 diabetes patients and individuals at high risk of metabolic syndrome. Arch Physiol Biochem 121: 178-186, 2015.

34. Madsen SM, Thorup AC, Overgaard K, and Jeppesen PB. High Intensity Interval Training Improves Glycaemic Control and Pancreatic $\beta$ Cell Function of Type 2 Diabetes Patients. PLoS One 10: e0133286, 2015.

35. McDonough P, Behnke BJ, Padilla DJ, Musch TI, and Poole DC. Control of microvascular oxygen pressures in rat muscles comprised of different fibre types. $J$ Physiol 563: 903-913, 2005.

36. Meyer K, Schwaibold M, Hajric R, Westbrook S, Ebfeld D, Leyk D, and Roskamm H. Delayed VO2 kinetics during ramp exercise: a criterion for cardiopulmonary exercise capacity in chronic heart failure. Med Sci Sports Exerc 30: 643-648, 1998.

37. Mitranun W, Deerochanawong C, Tanaka H, and Suksom D. Continuous vs interval training on glycemic control and macro- and microvascular reactivity in type 2 diabetic patients. Scand J Med Sci Sports 24: e69-76, 2014.

38. Morris N, Gass G, Thompson M, Bennett G, Basic D, and Morton H. Rate and amplitude of adaptation to intermittent and continuous exercise in older men. Med Sci Sports Exerc 34: 471-477, 2002.

39. Mortensen SP, Winding KM, Iepsen UW, Munch GW, Marcussen N, Hellsten Y, Pedersen BK, and Baum O. The effect of two exercise modalities on skeletal muscle capillary ultrastructure in individuals with type 2 diabetes. Scand J Med Sci Sports 29: 360-368, 2019.

40. Murias JM, Kowalchuk JM, and Paterson DH. Mechanisms for increases in V O2max with endurance training in older and young women. Med Sci Sports Exerc 42: 1891-1898, 2010. 41. Murias JM, Kowalchuk JM, and Paterson DH. Time course and mechanisms of adaptations in cardiorespiratory fitness with endurance training in older and young men. $J \mathrm{Appl}$ Physiol 108: 621-627, 2010.

42. O'Connor E, Green S, Kiely C, O'Shea D, and Egana M. Differential effects of age and type 2 diabetes on dynamic vs. peak response of pulmonary oxygen uptake during exercise. $J$ Appl Physiol (1985) 118: 1031-1039, 2015.

43. O'Connor E, Kiely C, O'Shea D, Green S, and Egaña M. Similar level of impairment in exercise performance and oxygen uptake kinetics in middle-aged men and women with type 2 diabetes. Am J Physiol Regul Integr Comp Physiol 303: R70-76, 2012.

44. O'Donovan G, Owen A, Bird SR, Kearney EM, Nevill AM, Jones DW, and WoolfMay K. Changes in cardiorespiratory fitness and coronary heart disease risk factors following 24 wk of moderate- or high-intensity exercise of equal energy cost. J Appl Physiol (1985) 98: 1619$1625,2005$.

45. Okushima D, Poole DC, Rossiter HB, Barstow TJ, Kondo N, Ohmae E, and Koga S. Muscle deoxygenation in the quadriceps during ramp incremental cycling: Deep vs. superficial heterogeneity. J Appl Physiol (1985) 119: 1313-1319, 2015.

46. Olver TD, and Laughlin MH. Endurance, interval sprint, and resistance exercise training: impact on microvascular dysfunction in type 2 diabetes. Am J Physiol Heart Circ Physiol 310: H337-350, 2016. 
655 DC. Effects of Type II diabetes on capillary hemodynamics in skeletal muscle. Am J Physiol Heart 656 Circ Physiol 291: H2439-2444, 2006.

657 48. Phillips BE, Kelly BM, Lilja M, Ponce-González JG, Brogan RJ, Morris DL, 658 Gustafsson T, Kraus WE, Atherton PJ, Vollaard NBJ, Rooyackers O, and Timmons JA. A 659 Practical and Time-Efficient High-Intensity Interval Training Program Modifies Cardio-Metabolic 660 Risk Factors in Adults with Risk Factors for Type II Diabetes. Front Endocrinol (Lausanne) 8: $661229,2017$.

662 49. Poitras VJ, Bentley RF, Hopkins-Rosseel DH, LaHaye SA, and Tschakovsky ME. 663 Independent effect of type 2 diabetes beyond characteristic comorbidities and medications on immediate but not continued knee extensor hyperaemia. Journal of Applied Physiology 119: 202212, 2015.

50. Regensteiner JG, Bauer TA, Reusch JE, Brandenburg SL, Sippel JM, Vogelsong AM, Smith S, Wolfel EE, Eckel RH, and Hiatt WR. Abnormal oxygen uptake kinetic responses in women with type II diabetes mellitus. J Appl Physiol 85: 310-317, 1998.

51. Revdal A, Hollekim-Strand SM, and Ingul CB. Can Time Efficient Exercise Improve Cardiometabolic Risk Factors in Type 2 Diabetes? A Pilot Study. J Sports Sci Med 15: 308-313, 2016.

52. Rocha J, Gildea N, O'Shea D, Green S, and Egaña M. Influence of priming exercise on oxygen uptake and muscle deoxygenation kinetics during moderate-intensity cycling in type 2 diabetes. J Appl Physiol (1985) 127: 1140-1149, 2019.

53. Ross R, Blair SN, Arena R, Church TS, Després JP, Franklin BA, Haskell WL, Kaminsky LA, Levine BD, Lavie CJ, Myers J, Niebauer J, Sallis R, Sawada SS, Sui X, and Wisløff U. Importance of Assessing Cardiorespiratory Fitness in Clinical Practice: A Case for Fitness as a Clinical Vital Sign: A Scientific Statement From the American Heart Association. Circulation 134: e653-e699, 2016.

54. Rowlands AV, Thomas PW, Eston RG, and Topping R. Validation of the RT3 triaxial accelerometer for the assessment of physical activity. Med Sci Sports Exerc 36: 518-524, 2004.

55. Saitoh T, Ferreira LF, Barstow TJ, Poole DC, Ooue A, Kondo N, and Koga S. Effects of prior heavy exercise on heterogeneity of muscle deoxygenation kinetics during subsequent heavy exercise. Am J Physiol Regul Integr Comp Physiol 297: R615-621, 2009.

56. Schreuder TH, Green DJ, Nyakayiru J, Hopman MT, and Thijssen DH. Time-course of vascular adaptations during 8 weeks of exercise training in subjects with type 2 diabetes and middle-aged controls. Eur J Appl Physiol 115: 187-196, 2015.

57. Spencer MD, Murias JM, and Paterson DH. Characterizing the profile of muscle deoxygenation during ramp incremental exercise in young men. Eur J Appl Physiol 112: 33493360, 2012.

58. Stutts WC. Physical activity determinants in adults. Perceived benefits, barriers, and self efficacy. Aaohn j 50: 499-507, 2002.

59. Takagi S, Murase N, Kime R, Niwayama M, Osada T, and Katsumura T. Aerobic training enhances muscle deoxygenation in early post-myocardial infarction. Eur J Appl Physiol 116: 673-685, 2016.

60. Terada T, Friesen A, Chahal BS, Bell GJ, McCargar LJ, and Boulé NG. Feasibility and preliminary efficacy of high intensity interval training in type 2 diabetes. Diabetes Res Clin Pract 99: 120-129, 2013. 
699 61. Thomas N, Alder E, and Leese GP. Barriers to physical activity in patients with diabetes.

700 Postgrad Med J 80: 287-291, 2004.

701 62. Vieth E. Fitting piecewise linear regression functions to biological responses. J Appl

702 Physiol (1985) 67: 390-396, 1989.

703 63. Weatherwax R, Harris N, Kilding AE, and Dalleck L. Time Course Changes in

704 Confirmed 'True' VO (2) max After Individualized and Standardized Training. Sports Med Int 705 Open 3: E32-e39, 2019.

706 64. Wei M, Gibbons LW, Kampert JB, Nichaman MZ, and Blair SN. Low 707 cardiorespiratory fitness and physical inactivity as predictors of mortality in men with type 2 708 diabetes. Ann Intern Med 132: 605-611, 2000.

709 65. Wilkerson DP, Poole DC, Jones AM, Fulford J, Mawson DM, Ball CI, and Shore AC.

710 Older type 2 diabetic males do not exhibit abnormal pulmonary oxygen uptake and muscle oxygen

711 utilization dynamics during submaximal cycling exercise. Am J Physiol Regul Integr Comp

712 Physiol 300: R685-692, 2011.

713 66. Williams CJ, Gurd BJ, Bonafiglia JT, Voisin S, Li Z, Harvey N, Croci I, Taylor JL, 714 Gajanand T, Ramos JS, Fassett RG, Little JP, Francois ME, Hearon CM, Jr., Sarma S, 715 Janssen S, Van Craenenbroeck EM, Beckers P, Cornelissen VA, Pattyn N, Howden EJ, 716 Keating SE, Bye A, Stensvold D, Wisloff U, Papadimitriou I, Yan X, Bishop DJ, Eynon N, 717 and Coombes JS. A Multi-Center Comparison of O(2peak) Trainability Between Interval

719 67. Wilson GA, Wilkins GT, Cotter JD, Lamberts RR, Lal S, and Baldi JC. HIIT Improves 720 Left Ventricular Exercise Response in Adults with Type 2 Diabetes. Med Sci Sports Exerc 2019.

721 68. Wilson GA, Wilkins GT, Cotter JD, Lamberts RR, Lal S, and Baldi JC. Impaired 722 ventricular filling limits cardiac reserve during submaximal exercise in people with type 2 diabetes. Cardiovascular Diabetology 16: 1-8, 2017.

69. Wilson GA, Wilson LC, Lamberts RR, Majeed K, Lal S, and Baldi JC. Beta-adrenergic responsiveness in the type 2 diabetic heart: effects on cardiac reserve. Medicine and Science in Sports and Exercise 49: 907-914, 2017.

70. Winding KM, Munch GW, Iepsen UW, Van Hall G, Pedersen BK, and Mortensen SP. The effect on glycaemic control of low-volume high-intensity interval training versus endurance training in individuals with type 2 diabetes. Diabetes Obes Metab 20: 1131-1139, 2018. 


\section{Figure captions}

732

733 Figure 1: Participant flow chart diagram.

734

735 Figure 2: Individual time course of changes in peak oxygen uptake $\left(\mathrm{V}_{2}{ }_{2 \text { peak }}\right)$ in the moderate736 intensity continuous training (MICT, $n=12$ ), high-intensity interval training (HIIT; $n=9$ ) and 737 non-exercising control $(n=9)$ groups. Thin lines are individual participants and thick lines represent the mean change in each group.

739

740

741

Figure 3: Mean time course of changes in peak oxygen uptake $\left(\dot{\mathrm{V}}_{2 \text { peak }}\right)$ and in the first $\% \Delta[\mathrm{HHb}+\mathrm{Mb}] / \% \mathrm{PO}$ slope (slope ${ }_{1}$ ) relative to the baseline or pretraining (panels $\mathrm{A}$ and $\mathrm{C}$ 742 respectively) and as a function of the total change (panels B and D respectively) in the moderateintensity continuous training (MICT, $n=12$ for panels A \& B; $n=10$ for panels $\mathrm{C} \& \mathrm{D}$ ) and highintensity interval training (HIIT, $n=9$ ) groups. Within panel A group differences did not reach statistical significance at wk $3(P=0.07)$, wk $9(P=0.22)$ or wk $12(P=0.14) . *$ significantly different from HIIT $(P<0.05)$.

747

748

Figure 4: Relationships between pretraining peak oxygen uptake ( $\left.\dot{\mathrm{VO}}_{2 \text { peak }}\right)$ and total changes in $749 \dot{\mathrm{V}}_{2 \text { peak }}$ across the 12-week intervention period in participants from the moderate-intensity 750 continuous training (MICT) and high-intensity interval training (HIIT) groups. The Pearson $r$ 751 (correlation) value and a line of best fit are shown for all data. 
753 Figure 5: Representative time course of changes in profiles of the modelled $[\mathrm{HHb}+\mathrm{Mb}]$ response 754 dynamics expressed as a function of relative power output (PO\%) during ramp incremental 755 exercise for individuals in the moderate-intensity continuous training (MICT) and high-intensity 756 interval training (HIIT) groups. Double linear regression models are superimposed on the data. 757 Note the larger first $\% \Delta[\mathrm{HHb}+\mathrm{Mb}] / \% \mathrm{PO}$ slope (slope ${ }_{1}$ ) of the double linear regression at the 758 pretraining time point in participants in the MICT and HIIT groups. The slopes within the control 759 group were not affected throughout the intervention.

760 
Table 1. Physical characteristics and activity levels.

\begin{tabular}{|c|c|c|c|}
\hline & MICT & HIIT & Control \\
\hline$n$ & 12 & 9 & 9 \\
\hline Sex (male, female), $n$ & 7,5 & 6,3 & 5,4 \\
\hline Age, yr & $53 \pm 10$ & $52 \pm 10$ & $54 \pm 9$ \\
\hline $\mathrm{BMI}, \mathrm{kg} / \mathrm{m}^{2}$ & $30.4 \pm 5.8$ & $28.7 \pm 3.0$ & $30.5 \pm 3.6$ \\
\hline $\begin{array}{l}\text { Time since diabetes } \\
\text { diagnosis, yr }\end{array}$ & $6.9 \pm 3.7$ & $6.6 \pm 3.5$ & $6.6 \pm 3.3$ \\
\hline $\mathrm{HbA}_{1 \mathrm{c}} \%$ & $6.8 \pm 0.5$ & $7.3 \pm 0.5$ & $6.8 \pm 1.0$ \\
\hline Fasting glucose, $\mathrm{mmol} / \mathrm{L}$ & $7.6 \pm 1.2$ & $9.3 \pm 3.3$ & $7.9 \pm 2.0$ \\
\hline Fat layer of $\mathrm{VL}, \mathrm{mm}$ & $7.7 \pm 3.9$ & $6.4 \pm 2.6$ & $8.6 \pm 3.2$ \\
\hline Resting SBP, $\mathrm{mmHg}$ & $121 \pm 16$ & $124 \pm 13$ & $130 \pm 12$ \\
\hline Resting DBP, $\mathrm{mmHg}$ & $75 \pm 9$ & $72 \pm 6$ & $73 \pm 7$ \\
\hline Resting HR, beats/min & $75 \pm 11$ & $73 \pm 9$ & $75 \pm 11$ \\
\hline \multicolumn{4}{|l|}{ Diabetes medication } \\
\hline Diet only, $n$ & & 1 & 1 \\
\hline Metformin, $n$ & 9 & 7 & 6 \\
\hline Sulfonylurea, $n$ & 2 & 3 & 2 \\
\hline DPP-4 inhibitor, $n$ & & & 2 \\
\hline GLP-1 analogues, $n$ & 1 & & 1 \\
\hline \multicolumn{4}{|l|}{$\begin{array}{l}\text { Anti-hypertensive } \\
\text { medication }\end{array}$} \\
\hline $\begin{array}{l}\text { Angiotensin converting } \\
\text { enzyme inhibitor, } n\end{array}$ & & 1 & \\
\hline $\begin{array}{l}\text { Angiotensin II receptor } \\
\text { blocker, } n\end{array}$ & 1 & & 1 \\
\hline Statins, $n$ & 5 & 3 & 3 \\
\hline \multicolumn{4}{|l|}{ Habitual physical activity } \\
\hline Inactive, h/day & $17.5 \pm 2.0$ & $17.4 \pm 2.9$ & $17.9 \pm 1.9$ \\
\hline Light, h/day & $5.7 \pm 1.6$ & $5.8 \pm 2.6$ & $5.4 \pm 1.1$ \\
\hline MVPA, h/day & $0.7 \pm 0.7$ & $0.7 \pm 0.3$ & $0.7 \pm 0.8$ \\
\hline
\end{tabular}

762 Data are mean \pm SD. BMI, body mass index; $\mathrm{HbA}_{1 \mathrm{c}}$, glycosylated haemoglobin; VL, vastus 763 lateralis; SBP, systolic blood pressure; DBP, diastolic blood pressure; HR, heart rate; DPP-4, 764 Dipeptidyl-peptidase 4; GLP-1, Glucagon-like peptide 1; MVPA, moderate-to-vigorous physical 765 activity. 
767 Table 2 Physiological responses during the ramp incremental test during the intervention for the

768 MICT, HIIT and control groups.

\begin{tabular}{|c|c|c|c|c|c|}
\hline & Pretraining & Week 3 & Week 6 & Week 9 & Posttraining \\
\hline \multicolumn{6}{|l|}{$\mathrm{PO}_{\text {peak }}, \mathrm{W}$} \\
\hline MICT & $155 \pm 54$ & $178 \pm 63^{*}$ & $185 \pm 64^{*}$ & $194 \pm 65^{*+}$ & $195 \pm 68^{* * \ddagger}$ \\
\hline HIIT & $187 \pm 51$ & $204 \pm 52^{*}$ & $216 \pm 52^{*+\#}$ & $220 \pm 50^{*+\#}$ & $217 \pm 55^{*+}$ \\
\hline Control & $148 \pm 49$ & $149 \pm 52$ & $146 \pm 55$ & $151 \pm 51$ & $153 \pm 50$ \\
\hline \multicolumn{6}{|c|}{$\dot{\mathrm{VO}}_{2 \text { peak, }} \mathrm{L} / \mathrm{min}$} \\
\hline MICT & $2.01 \pm 0.69$ & $2.31 \pm 0.71^{*}$ & $2.46 \pm 0.77^{* \#}$ & $2.37 \pm 0.75^{*}$ & $2.41 \pm 0.78^{*}$ \\
\hline HIIT & $2.31 \pm 0.51$ & $2.50 \pm 0.56^{*}$ & $2.54 \pm 0.52^{*}$ & $2.63 \pm 0.60^{*}$ & $2.59 \pm 0.54^{*}$ \\
\hline Control & $1.86 \pm 0.52$ & $1.94 \pm 0.63$ & $1.89 \pm 0.56$ & $1.94 \pm 0.64$ & $1.92 \pm 0.54$ \\
\hline \multicolumn{6}{|c|}{$\dot{\mathrm{VO}}_{2 \text { peak }}, \mathrm{mL} \cdot \mathrm{kg}^{-1} \cdot \mathrm{min}^{-1}$} \\
\hline MICT & $22.1 \pm 4.4$ & $25.9 \pm 5.5^{*}$ & $27.4 \pm 5.1^{* \#}$ & $27.0 \pm 5.5^{* \#}$ & $27.6 \pm 5.1^{* \#}$ \\
\hline HIIT & $26.4 \pm 4.0$ & $28.5 \pm 4.2^{* \#}$ & $29.2 \pm 3.5^{* \#}$ & $30.2 \pm 4.4^{* \#}$ & $30.0 \pm 4.0^{* \#}$ \\
\hline Control & $21.5 \pm 3.6$ & $22.1 \pm 4.4$ & $21.6 \pm 4.0$ & $22.2 \pm 4.2$ & $22.0 \pm 3.4$ \\
\hline \multicolumn{6}{|c|}{$H R_{\max }$, beats/min } \\
\hline $\mathrm{MICT}$ & $157 \pm 14$ & $158 \pm 14$ & $158 \pm 15$ & $160 \pm 17$ & $158 \pm 16$ \\
\hline HIIT & $162 \pm 13$ & $165 \pm 13$ & $162 \pm 13$ & $165 \pm 13$ & $162 \pm 15$ \\
\hline Control & $162 \pm 12$ & $157 \pm 15$ & $157 \pm 13$ & $158 \pm 16$ & $157 \pm 18$ \\
\hline \multicolumn{6}{|c|}{ Peak $\mathrm{O}_{2}$ pulse, $\mathrm{ml} /$ beat } \\
\hline $\mathrm{MICT}$ & $12.8 \pm 4.1$ & $14.9 \pm 4.1^{*}$ & $15.7 \pm 4.3^{* \#}$ & $15.1 \pm 4.4^{*}$ & $15.5 \pm 4.5^{*}$ \\
\hline HIIT & $14.4 \pm 3.3$ & $15.2 \pm 3.6^{*}$ & $15.8 \pm 3.4^{*}$ & $16.1 \pm 4.1^{*}$ & $16.3 \pm 4.0^{*}$ \\
\hline Control & $11.3 \pm 3.2$ & $12.4 \pm 3.4$ & $12.2 \pm 2.9$ & $12.2 \pm 3.5$ & $12.2 \pm 3.0$ \\
\hline \multicolumn{6}{|c|}{$\dot{\mathrm{V}} \mathrm{CO}_{2 \text { peak, }} \mathrm{L} / \mathrm{min}^{\mathrm{a}}$} \\
\hline MICT & $2.30 \pm 0.82$ & $2.59 \pm 0.73$ & $2.74 \pm 0.80$ & $2.71 \pm 0.79$ & $2.77 \pm 0.98$ \\
\hline HIIT & $2.69 \pm 0.59$ & $2.97 \pm 0.75$ & $2.98 \pm 0.78$ & $3.22 \pm 0.80$ & $3.01 \pm 0.63$ \\
\hline Control & $1.86 \pm 0.52$ & $1.94 \pm 0.63$ & $1.89 \pm 0.56$ & $1.94 \pm 0.64$ & $1.92 \pm 0.54$ \\
\hline \multicolumn{6}{|c|}{$\dot{\mathrm{V}} \mathrm{E}_{\text {peak }} \mathrm{L} / \mathrm{min}^{\mathrm{a}}$} \\
\hline MICT & $76 \pm 28$ & $86 \pm 27$ & $88 \pm 25$ & $90 \pm 25$ & $89 \pm 21$ \\
\hline HIIT & $84 \pm 18$ & $92 \pm 20$ & $92 \pm 27$ & $96 \pm 24$ & $97 \pm 25$ \\
\hline Control & $69 \pm 15$ & $72 \pm 22$ & $72 \pm 31$ & $71 \pm 26$ & $73 \pm 21$ \\
\hline \multicolumn{6}{|l|}{ RER } \\
\hline MICT & $1.14 \pm 0.10$ & $1.13 \pm 0.05$ & $1.12 \pm 0.08$ & $1.13 \pm 0.06$ & $1.16 \pm 0.09$ \\
\hline HIIT b & $1.16 \pm 0.05$ & $1.22 \pm 0.06$ & $1.18 \pm 0.07$ & $1.22 \pm 0.06$ & $1.19 \pm 0.06$ \\
\hline Control & $1.13 \pm 0.07$ & $1.12 \pm 0.10$ & $1.13 \pm 0.11$ & $1.11 \pm 0.09$ & $1.11 \pm 0.06$ \\
\hline \multicolumn{6}{|l|}{ MRT, $\mathrm{s}^{\mathrm{c}}$} \\
\hline MICT & $78 \pm 46$ & $67 \pm 39$ & $52 \pm 43$ & $42 \pm 35$ & $49 \pm 25$ \\
\hline HIIT & $78 \pm 37$ & $58 \pm 25$ & $59 \pm 50$ & $40 \pm 29$ & $49 \pm 20$ \\
\hline Control & $76 \pm 37$ & $78 \pm 50$ & $78 \pm 53$ & $71 \pm 51$ & $72 \pm 27$ \\
\hline \multicolumn{6}{|c|}{ PO @ VT, W } \\
\hline MICT & $91 \pm 32$ & $111 \pm 42^{*}$ & $123 \pm 45^{*+\#}$ & $132 \pm 47^{*+\#}$ & $131 \pm 44^{*+\#}$ \\
\hline HIIT & $115 \pm 32$ & $129 \pm 34^{* \#}$ & $142 \pm 37^{*+\#}$ & $145 \pm 34^{*+\#}$ & $148 \pm 43^{*+\#}$ \\
\hline
\end{tabular}




\begin{tabular}{|c|c|c|c|c|c|}
\hline Control & $83 \pm 25$ & $83 \pm 20$ & $87 \pm 27$ & $82 \pm 26$ & $90 \pm 27$ \\
\hline
\end{tabular}

770 dioxide production; $\dot{\mathrm{VE}}$, minute ventilation; RER, respiratory exchange ration; MRT, mean

771 response time; VT, ventilatory threshold. * Significantly different from week $0(P<0.05)$; ${ }^{\dagger}$

772 significantly different from week $3(P<0.05) ;{ }^{\ddagger}$ significantly different from week $6(P<0.05)$;

$773 \quad{ }^{\#}$ significantly different from control $(P<0.05) ;{ }^{\text {a }}$ significantly different at pretraining than all other

774 timepoints $(P<0.05){ }^{\mathrm{b}}{ }^{\mathrm{b}}$ significantly different from MICT \& Control $(P<0.05){ }^{\mathrm{c}}{ }^{\mathrm{c}}$ significantly

775 different at week 9 compared with pretraining $(P<0.05)$. 
778 Table 3 Parameter estimates for the $\%[H H b+M b]$ profile for all groups plotted as a function of 779 normalised $\mathrm{PO}(\%)$ as well as the rate of increase in $\dot{\mathrm{V}} \mathrm{O}_{2}$ relative to $\mathrm{PO}$ (i.e. $\triangle \dot{V} \mathrm{O}_{2} / \Delta P O$ ) during 780 ramp incremental test throughout the intervention period.

781

\begin{tabular}{|c|c|c|c|c|c|}
\hline & Pretraining & Week 3 & Week 6 & Week 9 & Posttraining \\
\hline Slope $_{1}$ & & & & & \\
\hline MICT & $1.96 \pm 0.60$ & $1.40 \pm 0.19^{* \#}$ & $1.41 \pm 0.32^{*}$ & $1.36 \pm 0.29^{* \#}$ & $1.37 \pm 0.22^{* \#}$ \\
\hline HIIT & $1.89 \pm 0.63$ & $1.35 \pm 0.49^{*}$ & $1.43 \pm 0.39^{*}$ & $1.28 \pm 0.24^{* \#}$ & $1.31 \pm 0.12^{* \#}$ \\
\hline Control & $1.80 \pm 0.49$ & $1.83 \pm 0.45$ & $1.80 \pm 0.38$ & $1.83 \pm 0.53$ & $1.85 \pm 0.25$ \\
\hline Slope $_{2}$ & & & & & \\
\hline MICT & $0.21 \pm 0.31$ & $0.15 \pm 0.20$ & $0.11 \pm 0.24$ & $0.12 \pm 0.17$ & $0.07 \pm 0.57$ \\
\hline HIIT & $-0.1 \pm 0.56$ & $0.15 \pm 0.17$ & $0.19 \pm 0.23$ & $0.14 \pm 0.19$ & $-0.08 \pm 0.47$ \\
\hline Control & $0.00 \pm 0.53$ & $0.18 \pm 0.55$ & $0.07 \pm 0.27$ & $0.04 \pm 0.28$ & $-0.08 \pm 0.63$ \\
\hline BP, \% PO & \multicolumn{5}{|l}{} \\
\hline MICT & $72.2 \pm 14.3$ & $75.5 \pm 14.9$ & $73.4 \pm 17.2$ & $75.3 \pm 14.5$ & $78.6 \pm 10.2$ \\
\hline HIIT & $77.4 \pm 13.4$ & $75.4 \pm 15.6$ & $74.9 \pm 14.1$ & $74.0 \pm 17.7$ & $78.7 \pm 7.9$ \\
\hline Control & $74.5 \pm 16.3$ & $72.4 \pm 11.1$ & $70.8 \pm 19.7$ & $71.7 \pm 11.8$ & $71.4 \pm 15.2$ \\
\hline$\Delta \dot{V O}_{2} / \Delta \mathrm{PO}, \mathrm{mL}^{*} \mathrm{~min}^{-1} \cdot \mathrm{W}^{-1}$ & \multicolumn{5}{|l|}{} \\
\hline MICT & $9.1 \pm 1.4$ & $9.9 \pm 1.5$ & $10.3 \pm 1.6$ & $10.1 \pm 1.8$ & $9.6 \pm 1.6$ \\
\hline HIIT & $9.5 \pm 1.1$ & $9.2 \pm 1.5$ & $9.5 \pm 0.6$ & $9.7 \pm 0.8$ & $9.8 \pm 0.9$ \\
\hline Control & $9.2 \pm 1.1$ & $9.4 \pm 1.1$ & $9.0 \pm 1.8$ & $9.1 \pm 2.1$ & $9.1 \pm 1.3$ \\
\hline
\end{tabular}

Data are mean (SD). Slope 1 and slope ${ }_{2}$ are the slopes of the double linear regression before and

783

784

785

786

787

788 after the break point (BP) respectively. $\mathrm{PO}$, power output; $\dot{\mathrm{VO}}_{2}$, oxygen consumption. The $\Delta \dot{\mathrm{VO}}_{2} / \Delta \mathrm{PO}$ slope was calculated over the same range of $\mathrm{PO}$ as used to determine the first $\% \Delta[\mathrm{HHb}+\mathrm{Mb}] / \% \mathrm{PO}$ slope ( slope $_{1}$ ).

* Significantly different from week $0(P<0.05)^{\#}$ significantly different from control $(P<0.05)$. 
Fig 1

Enrolment

Pre-screened
$(n=300)$

Screened/assessed for digibility
\[ (n=59) \]

Excluded $(n=24)$

-Not meeting imclusion criteria $(n=12)$

- Declined to participate $(n=12)$

Randomized

$(n=35)$

Allocation

Allocated to Control interventio

$(n=12)$

Allocated to MICT intervention

$(n=13)$

Allocated to HIIT intervention

$(n=10)$

Follow-up

Discontinued intervention $(n=3)$ - Due to personal reasons

Discontinued intervention $(n=2)$ - Due to personal reasons

Discontinned intervention $(n=3)$ -Due to persongl reasong

Re-allocated to training $(n=3)$

$-\operatorname{MICT}(n=1)$

- HIIT $(n=2)$

Analysis

Anslyzed ( $n=9)$

Analyned ( $n=12)$

Analyned ( $n=9)$ 
Fig 2
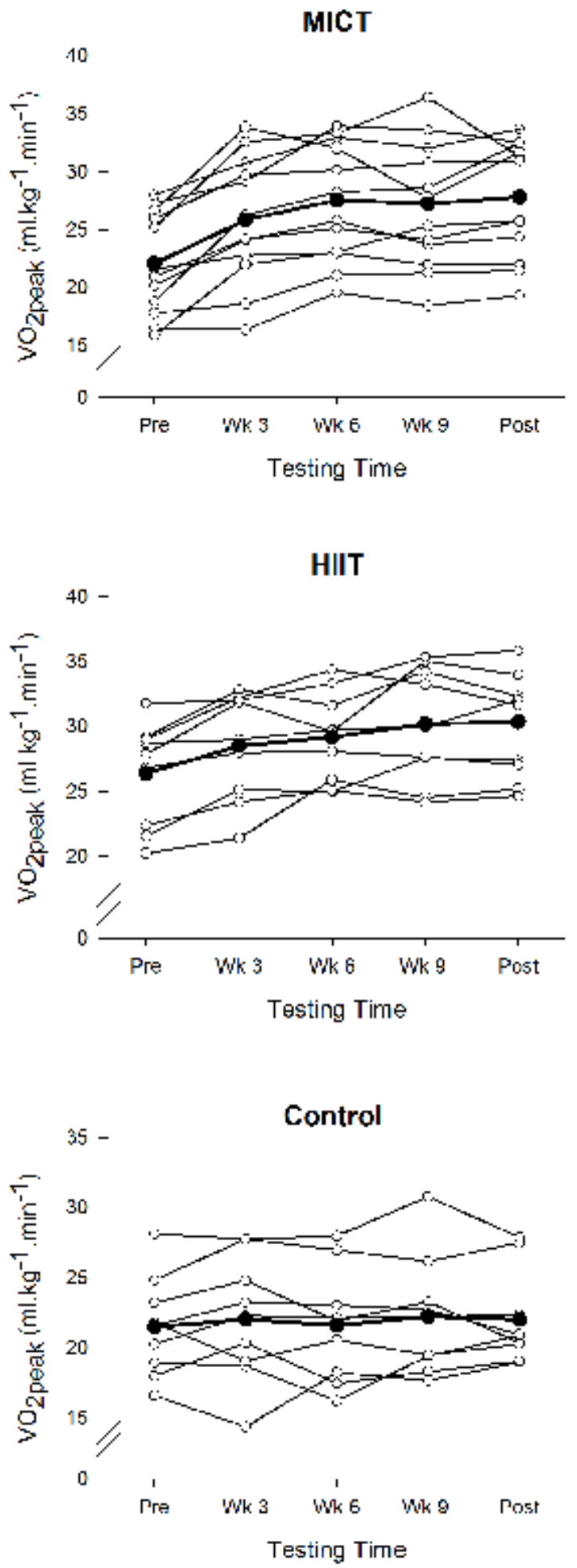
Fig 3 A
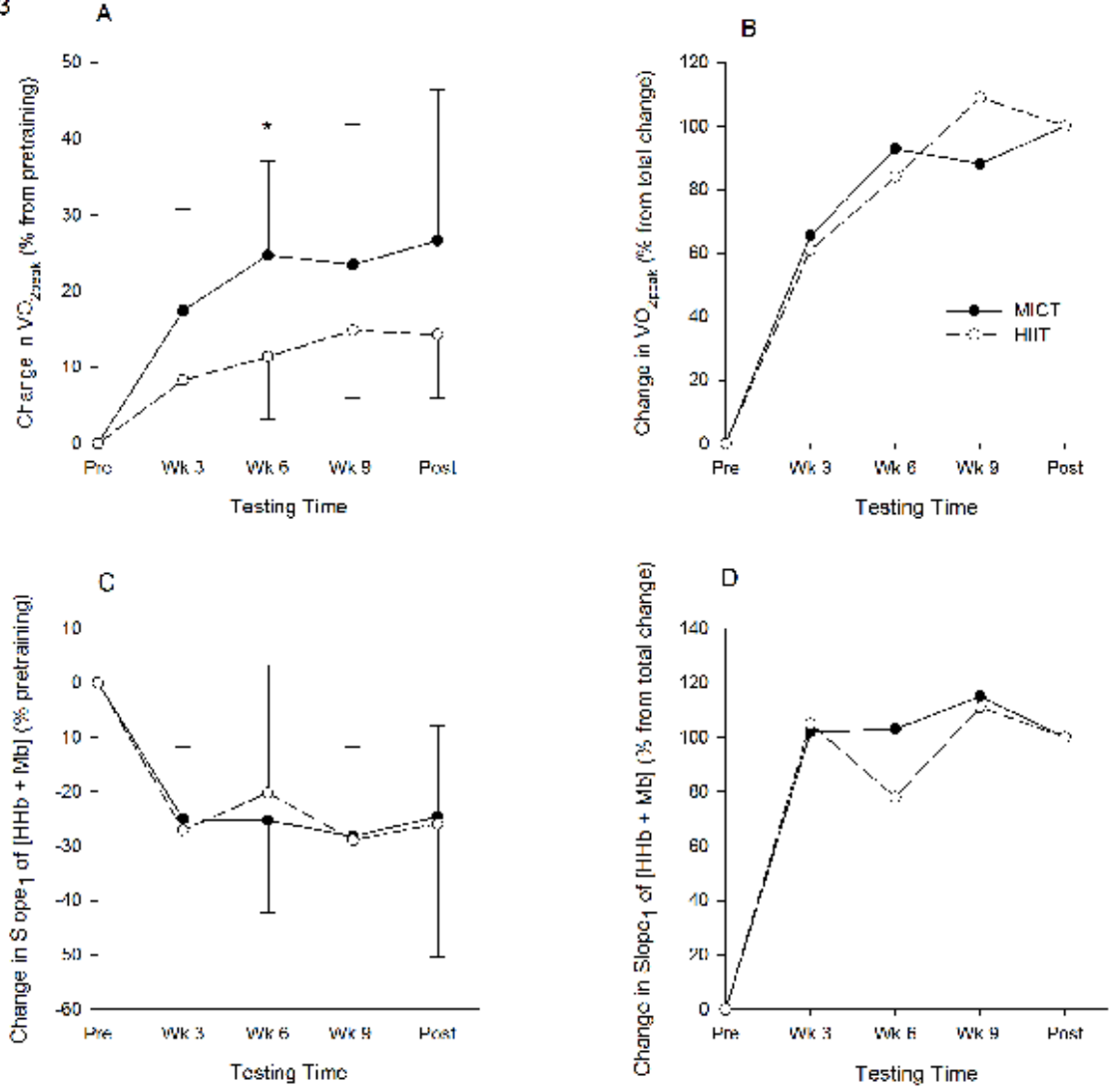
Fig 4

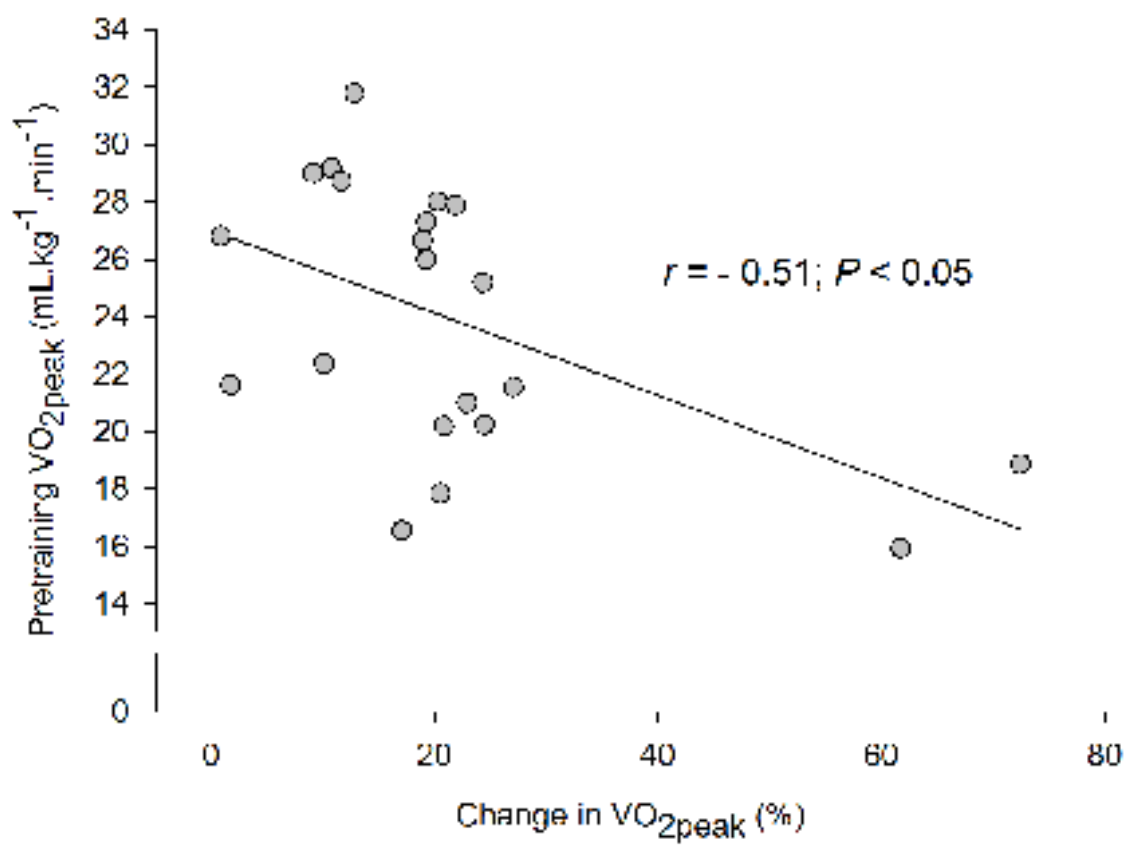


Fig. 5
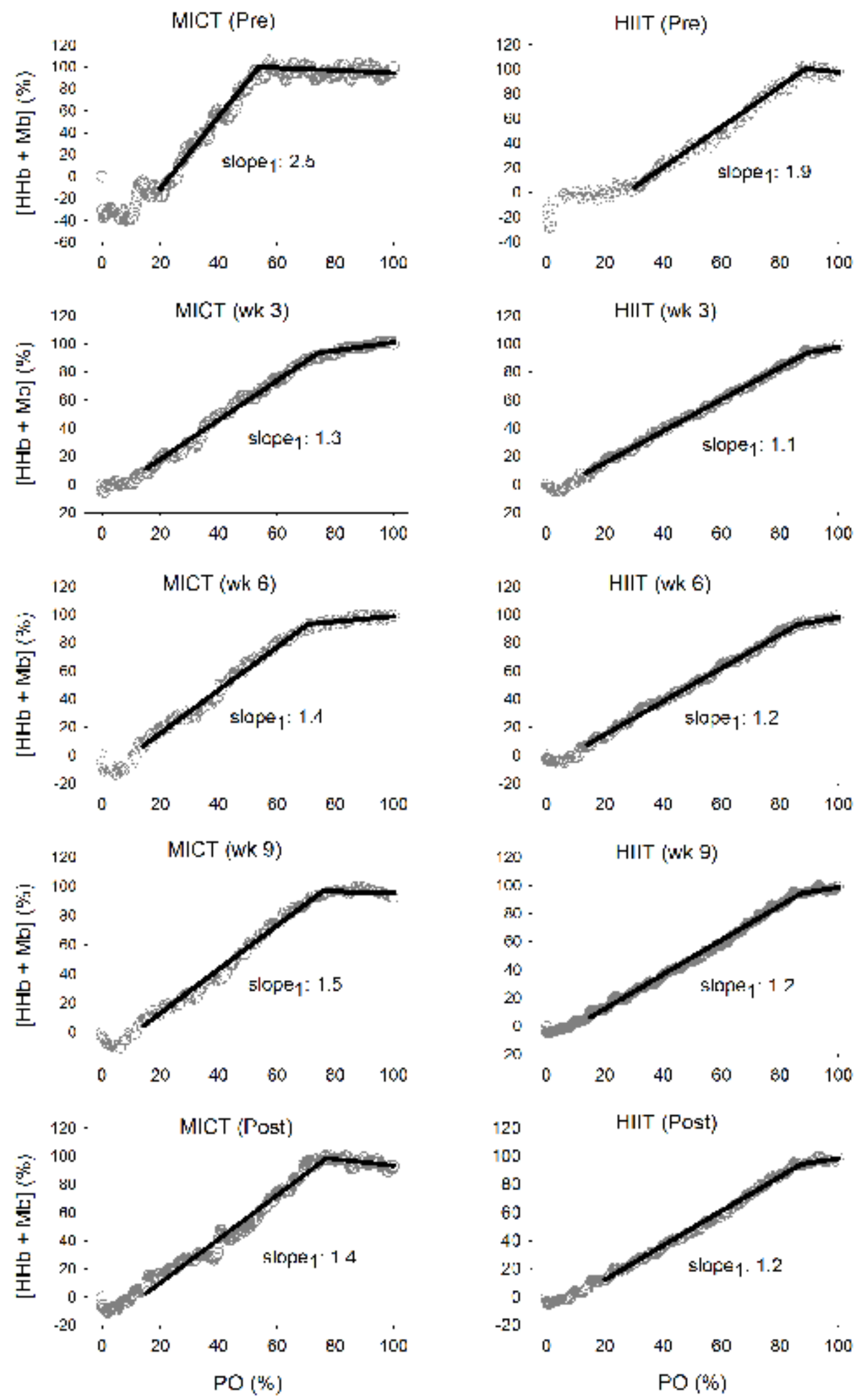